\title{
Biogeographical kinetics on an island volcano (Cape- linhos, Azores): fast colonisation rates and dominance of arthropod exotic species
}

\author{
SIMONE FATTORINI ${ }^{1,2}$ and PAULO A. V. BORGES ${ }^{1}{ }^{1}$ Departamento de Ciências Agrá- \\ rias - CITAA (Azorean Biodiversity Group), Universidade dos Açores, Angra do Heró́smo, Portugal and ${ }^{2}$ Water Ecology \\ Team, Department of Biotechnology and Biosciences, University of Milano Bicocca, Milan, Italy
}

\begin{abstract}
The aim of this paper was to investigate the arthropod colonisation of a recently erupted volcano in the framework of a general model of colonisation kinetics.

2. We analysed the diversity of arthropod communities at three locations on Faial Island (Azores) using a well-defined disturbance gradient: (i) a site that is new land added by the eruption of Capelinhos Volcano of 1957; (ii) a site moderately affected by this eruption; and (iii) a pristine site not affected. We calculated the recolonisation times at the disturbed sites using species richness at the undisturbed site as an equilibrium value (last erupted 900-1000 years ago).

3. Species with different distributional ranges (endemic, native non-endemic and introduced) have different colonisation kinetics. Introduced exotic species were particularly rapid in colonising the erupted volcano, reaching a number of species greater than that observed in the undisturbed area. By contrast, native non-endemic species had more difficulty in recolonising the erupted area, and no endemic has reached it. The volcano community is dominated by a few species with high abundance and shows low richness and strong dominance in comparison with the undisturbed community. The moderately disturbed site supports a rich and well-balanced arthropod community.

4. Although the erupted volcano has a species richness even slightly higher than the undisturbed site, this is a consequence of the high colonisation ability of introduced species, and its arthropod community is strongly disharmonic.
\end{abstract}

Key words. Azorean Islands, community ecology, ecological succession, equilibrium theory, recolonisation, volcanic eruption.

\section{Introduction}

Each archipelago has its own colonisation and evolutionary histories that filter species both arriving at long-distance dispersal and brought accidentally by man (Ricklefs, 2008). Classical models of island biogeography postulate that insular species assemblages are random samples drawn from a pool of potential colonists and that species richness increases with time to an equi-

Correspondence: Simone Fattorini, Water Ecology Team, Department of Biotechnology and Biosciences, University of Milano Bicocca, Piazza della Scienza 2, I-20126 Milan, Italy.

E-mail: simone_fattorini@virgilio.it librium value, corresponding to the saturation of available niches (see Whittaker \& Fernández-Palacios, 2007). Earlier evidence of saturation in animal assemblages was reported for island birds in the Caribbean (Terborgh \& Faaborgh, 1980) and fish assemblages in lakes (Tonn et al., 1990), but many more examples can be listed (reviewed by Srivastava, 1999). More recently, Winkler and Kampichler (2000), Soares et al. (2001) and Borges and Brown (2004) found saturation patterns at a local scale, respectively, in grassland Collembola, litter ant communities and pasture spiders. However, this could indicate pseudo-saturation (i.e. the appearance of saturation by an unsaturated community) owing to small-scale effects and uncertainty in local species richness estimates (Caley \& Schluter, 1997), and

(C) 2011 The Authors 
recent studies on local-regional processes show that most local communities are not saturated (see Loreau, 2000). For example, there is evidence that isolated oceanic islands may be not saturated with species, especially the recent ones, if there was not sufficient time for a complete colonisation (Borges \& Brown, 1999; Borges \& Hortal, 2009), the empty niche space being filled in historical times by recently introduced species (see e.g., Schaefer et al., 2011, showing that introduced plant species are more likely to become invasive in the absence of closely related species in the native flora of the Azores).

As a consequence of the dispersal difficulties imposed by the isolation of many remote volcanic archipelagos, as well as the destructive influence of volcanic activity and, more recently, of human activities, most islands are probably in a non-equilibrium condition (see Whittaker, 1995). Therefore, regional processes are critical to local community assembly (Ricklefs, 2008), and the rate of saturation will vary according to the characteristics of the system under study (dispersal ability of the species, isolation, habitat diversity, etc.).

In a recent paper, Fattorini (2010) used the approach developed by Diamond (1972) in the framework of the equilibrium theory of island biogeography of MacArthur and Wilson (1967) to investigate the recolonisation kinetics of island and mainland volcanoes. The main critical point in that paper was the estimation of the equilibrial value of species richness, i.e. the expected value of species richness for the erupted volcano at the end of the recolonisation process, when ecosystems will be completely restored and equilibrium reached. Studies on volcanic eruptions are retrospective in nature, because data on plant and animal communities on the volcanic area before the eruption are lacking, and in case of volcanoes emerged from the sea, it is obvious that there were no communities before eruption. Thus, to estimate characteristics of communities at equilibrium, one must refer to a pristine (undisturbed) site which is considered an equilibrium counterpart of the erupted volcano (see Thornton, 2007). For island volcanoes, i.e., volcanic islands that were almost completely devastated by recent eruption, Fattorini (2010) used species richness from adjacent islands of similar area not affected by recent eruptions, while for a mainland volcano, he calculated the expected value at equilibrium from sites of different size and locations using a species-area relationship. These estimates are subject to several possible source of errors: (i) incompleteness of faunal inventories of the reference sites; (ii) problems attached to the use of parameters of the species-area function to account for differences in area size among sites; and (iii) differences in the ecological settings of the areas used as equilibrium reference because of their distance from the study site (e.g. differences in altitude, climate, etc.). These problems (which are typical of most studies on volcano recolonisation) were discussed in Fattorini's paper, showing the limits to current data and demonstrating how precise the data will have to be to fully and convincingly document the processes postulated. We believe that at a time when research on island biogeography is flowering (Stuessy, 2007; Whittaker \& Fernández-Palacios, 2007; Gillespie \& Clague, 2009; Losos \& Ricklefs, 2009) and when interest in volcanic islands is especially high (Whittaker et al., 2008, 2009; Borges \& Hortal, 2009; Cardoso et al., 2010; Meijer et al.,
2011), studies based on more robust data may be particularly useful to elucidate (re)colonisation processes.

In this paper, we take advantage of recent standardised sampling on the Azorean Islands (see, e.g., Borges et al., 2005, 2006) to investigate the arthropod colonisation of a recently erupted volcano. We will address some of the shortcomings of previous works and add further momentum to the development of a general model of colonisation kinetics. Because of the lack of abundance data, all conclusions drawn by Fattorini were based only on species richness. Here, we also used abundance data to test his predictions on the evolution of community structure during colonisation.

\section{Materials and methods}

\section{Study sites}

We analysed the arthropod recolonisation of Capelinhos Volcano, on the Azorean island of Faial. Faial is a young island $(0.7 \mathrm{Ma})$ of small size $\left(172 \mathrm{~km}^{2}\right)$ dominated by a central large caldera (1043 m above sea level - 'Caldeira do Faial') and located in the Azorean microplate. Several cinder cones are located on the sides of the Caldeira do Faial. Capelinhos Volcano is the most recent volcano from the Azores (1957-1958), exploding dramatically in 1957 with a devastating underwater eruption. The volcano had two main phases, one explosive (phreatomagmatic) and the second Strombolian, i.e., an activity with low explosivity and affecting only the area closest to the volcano (see Forjaz, 2007 for details). As a result of these eruptions, a large amount of ashes of the first phase covered the western part of Faial and a total of $2.5 \mathrm{~km}^{2}$ of new land was added to the island (Machado et al., 1962).

The Capelinhos Volcano is a relatively small volcano within an island. From this respect, it differs considerably from the two main types of volcanoes discussed by Fattorini (2010): volcanoes on mainlands, and island volcanoes, i.e., islands that are entirely constituted by a large volcano and which are virtually sterilised by volcanic eruptions. In the case of Capelinhos Volcano, the volcanic eruption had some major impact in the western part of the island of Faial, but other places remained more or less undisturbed. This particular condition allowed us to eliminate some possible confounding factors that affected previous research. The use of an undisturbed site on the same island of Faial as a reference for the equilibrium conditions avoided problems owing to differences in ecological settings which can affect comparisons between distant sites. Thus, in our 'natural experiment,' we can assume that all differences between Capelinhos Volcano (treated site) and the undisturbed (control) site can unambiguously be attributed to the 'treatment' (i.e., the eruption). Another advantage of our study system is that the volcano is placed on an island, so we can be confident that the species pool of the control site is the actual source of species for recolonisation, because colonisation from other islands or the mainland is definitively less probable in the timescale in evaluation. The only limitation of our study is the fact that the undisturbed (control) site is located at a different altitude, but we also selected a nearby site 
with intermediate disturbance and located at lower altitude, which allows an improved comparison.

To compare the fauna of Capelinhos Volcano with that of an undisturbed site, we selected a patch of native vegetation in the protected area of Caldeira do Faial, which is placed at about $10 \mathrm{~km}$ from the Capelinhos Volcano and which has not been particularly affected by Capelinhos eruption (Forjaz, 2007). The last eruption in this old volcano was about 900-1000 years ago. We have also considered a third site, Cabeço do Fogo, placed between Capelinhos and Caldeira do Faial. This site is also the result of a historical eruption of Strombolian type affecting mainly the surrounding area (1672-1673) and was moderately affected by the more recent Capelinhos eruption. Thus, it can be considered a 'spatial' representation of what is expected, from a 'temporal' point of view, at an intermediate stage of recolonisation. In fact, all the terrain in Cabeço do Fogo is covered with ashes from the Capelinhos Volcano, and the vegetation is secondary composed of both native and exotic plants.

\section{Sampling procedure}

In all three sites, sampling was conducted using a standardised protocol. In summary, at each site, we laid out two independent and randomly located 150-m-long, 5-m-wide transects. We sampled the epigean arthropod fauna using pitfall traps set in the ground for at least a 2-week period during summer months. The traps consisted of plastic cups with a top diameter of 42 and $78 \mathrm{~mm}$ deep, dug into the ground, so the lip was flush with the soil surface. Half of the traps $(n=15)$ were filled with approximately $60 \mathrm{ml}$ of a non-attractive solution (antifreeze liquid) with a small proportion of ethylene glycol and the other half $(n=15)$ with the same volume of a general attractive solution (Turquin mixture), which was made of dark beer and some preservatives. In both kinds of traps, a few drops of a liquid detergent were added to reduce surface tension. Traps were spaced $5 \mathrm{~m}$ from one another, starting with a Turquin trap and alternating with the ethylene traps. We used both Turquin traps and ethylene glycol traps not only to survey the relative abundance of each species sampled (with non-attractive traps) but also to capture the maximum number of species (with attractive traps). Use of pitfall traps (especially if baited) is particularly efficient in recovering a high proportion of total species richness even in a short sampling period and represents thus an excellent way for a rapid biodiversity assessment (see Biaggini et al., 2007; Fattorini, 2009; and estimates of sampled richness reported below). For more details on this survey, see studies of Borges et al. (2005) and Gaspar et al. (2008). For the current purpose, we selected the two available transects from the Capelinhos Volcano and for comparison two of the four available transects of Cabeço do Fogo and Caldeira do Faial fragments.

All Araneae, Opiliones, Pseudoscorpiones and insects (excluding Collembola, Diplura, Diptera and Hymenoptera) were initially sorted into morphospecies by a team of trained persons and later identified to species (with few exceptions) by expert taxonomists. On the basis of their geographical distribution, species were sorted into the following three categories: (i) endemic (species restricted to the Azorean Islands); (ii) native non-endemic (species whose occurrence on the Azorean Islands cannot be associated with human activities and that are also known from other regions); and (iii) introduced (those proved to have arrived to the Azorean Islands as a result of human activities and which generally have a cosmopolitan distribution). This categorisation reflects species ecological plasticity and colonisation abilities, increasing from endemic to introduced ones. Primary data are given as Appendix S1.

\section{Analyses}

To evaluate the completeness of species inventories used here, we applied two procedures. First, we calculated the estimated richness at each site using Chaol estimator and then calculated completeness as the observed to estimated richness ratio. The obtained values suggest that a large fraction $(0.71-0.93)$ of estimated total richness was sampled. For each sampling site, we also constructed an accumulation curve (not shown). All curves were sample-based and rescaled to individuals as suggested by Gotelli and Colwell (2001), using a total of 1000 randomisations. The final slopes of the curves were calculated as in the study of Cardoso et al. (2008):

$$
\text { Slope }=1 /\left(n_{S}-n_{S-1}\right)
$$

where $n_{S}=$ final number of individuals for each curve (corresponding to the total richness value $S$ ) and $n_{S-1}=$ number of individuals corresponding to the point in the curve where the final single species was added (corresponding to a richness value of $S-1)$ (Cardoso et al., 2008).

The results showed high values of sampling intensity and negative slopes for the final part of the Chao 1 curves: Capelinhos Volcano: -0.04; Cabeço do Fogo: -0.0006; and Caldeira do Faial: -0.06 , which means that we attained a saturation. These results indicate that species were adequately sampled and allow direct comparisons of richness and abundance between sites.

To test whether the proportion of endemic, native and introduced species varied among the three sites, we used $G$-tests.

For each site, we also calculated five indexes of diversity. Because no single diversity index encompasses all the characteristics of an ideal index (Magurran, 1988; Krebs, 1999), a combination of them that reflects richness, dominance and evenness was used. Thus, the following community parameters were calculated for each taxon to compare communities of the three sites:

- Simpson dominance index: $C=\sum\left(\frac{n_{i}}{n}\right)^{2}$ where $n_{i}$ is number of individuals of taxon $i$. $C$ varies from 0 (all taxa are equally present) to 1 (One taxon dominates the community completely).

- Shannon index (entropy): $H=-\sum \frac{n_{i}}{n} \ln \left(\frac{n_{i}}{n}\right) \cdot H$ ranges from 0 (one taxon dominates the community completely) to high values for communities with many taxa, each with few individuals.

- Buzas and Gibson's evenness: $e^{H} / S$ (where $S$ is the number of species). 
- Simpson diversity index: $D=1-C . D$ measures the 'evenness' of the community from 0 to 1 .

- Pielou's equitability (evenness): $J=H / \ln S$.

Properties of these indexes are discussed by Legendre and Legendre (1998), Magurran (1988, 2004) and Hayek and Buzas (2010).

To compare diversity indexes of the three sites in pairwise combinations, we applied two different randomisation procedures: bootstrapping and permutation. In the bootstrapping, the two samples A and B were initially pooled. Then, 1000 random pairs of samples $\left(\mathrm{A}_{i}, \mathrm{~B}_{i}\right)$ were taken from this pool, and a diversity index was calculated for each replicate pair with the same numbers of individuals as in the original two samples. In the permutation procedure, 1000 random matrices with two columns (samples) were generated, each with the same row and column totals as in the original data matrix. In both cases, the probability of obtaining the observed difference by random sampling from a unique parental population was calculated as the number of times that the absolute difference of the indexes of a replicate pair exceeded or equalled that of the original samples. A $P($ equal $)<0.05$ was assumed to indicate a significant difference in diversity index between the two samples under test. Because the two procedures gave virtually identical probability values, we will not discuss further this point. Calculations were made using PAST (Hammer et al., 2001).

To estimate recolonisation times, we used the model developed by Diamond (1972) and recently applied to mainland and island volcanoes by Fattorini (2010). If a fauna is completely destroyed by a volcanic eruption, the relaxation time $\left(t_{r}\right)$, i.e. the length of time required to reach $36.8 \%$ of the equilibrium value after the perturbation, can be easily calculated from the following equation:

$$
t_{r}=-t / \log _{\mathrm{e}}\left[1-\left(S(t) / S_{\mathrm{eq}}\right)\right]
$$

$S(t)$ is species number at time $t$ from the volcanic eruption and $S_{\text {eq }}$ is the number of species at equilibrium. Relaxation is $90 \%$ complete after 2.303 relaxation times (see Fattorini, 2010; for details). It is important to note that this particular sense of the expression 'relaxation time' is not restricted to differential species extinction but has a more general application, also including recolonisation rate after perturbation (Diamond, 1972).

To calculate recolonisation times of Capelinhos Volcano, we used species richness of Caldeira do Faial as equilibrium value. We conducted all analyses for the entire arthropod data set, because most taxa were represented by too few species for more detailed analyses.

Finally, we have performed similarity analyses between sites to investigate the effect of volcanic explosion on species composition. Between-site similarity was calculated using several similarity indexes among the most commonly applied in community ecology and biogeography, such as Jaccard, Dice and Kulczynski 2 (for a discussion see Shi, 1993; Hausdorf \& Hennig, 2005). All these indices produced virtually identical results, so we will show only those obtained with Jaccard index, which is the most known and easiest to understand. We conducted separate analyses for native non-endemic and introduced species, but not for endemics because no endemic species was found on the erupted volcano.

\section{Results}

The number of species of the erupted volcano was slightly greater than that recorded for the undisturbed site (Table 1). The moderately disturbed site had the highest value of species richness (Table 1).

Proportions of endemic, native and introduced species varied considerably among the three sites (Fig. 1). The erupted volcano had the highest proportion of introduced species and had no endemic species, showing significant differences when compared with the moderately disturbed site $(G$-test $=6.767, P<0.05)$ and with the undisturbed site $(G$-test $=7.126, P<0.05)$. By

Table 1. Values of the structural parameters of the arthropod communities in three sampling sites with different degrees of volcanic disturbance on the Faial Island (Azores).

\begin{tabular}{lccc}
\hline Parameter & $\begin{array}{l}\text { Erupted } \\
\text { volcano }\end{array}$ & $\begin{array}{l}\text { Moderately } \\
\text { disturbed site }\end{array}$ & $\begin{array}{l}\text { Undisturbed } \\
\text { site }\end{array}$ \\
\hline$S$ & 26 & 44 & 24 \\
$C$ & 0.336 & 0.341 & 0.162 \\
$H$ & 1.794 & 1.586 & 2.350 \\
$e^{H} / S$ & 0.231 & 0.111 & 0.437 \\
$D$ & 0.664 & 0.659 & 0.838 \\
$J$ & 0.551 & 0.419 & 0.739 \\
\hline
\end{tabular}

$S$, species richness; $C$, Simpson dominance index; $H$, Shannon index; $e^{H} / S$, Buzas and Gibson's evenness; $D$, Simpson diversity index; $J$, Pielou equitability.

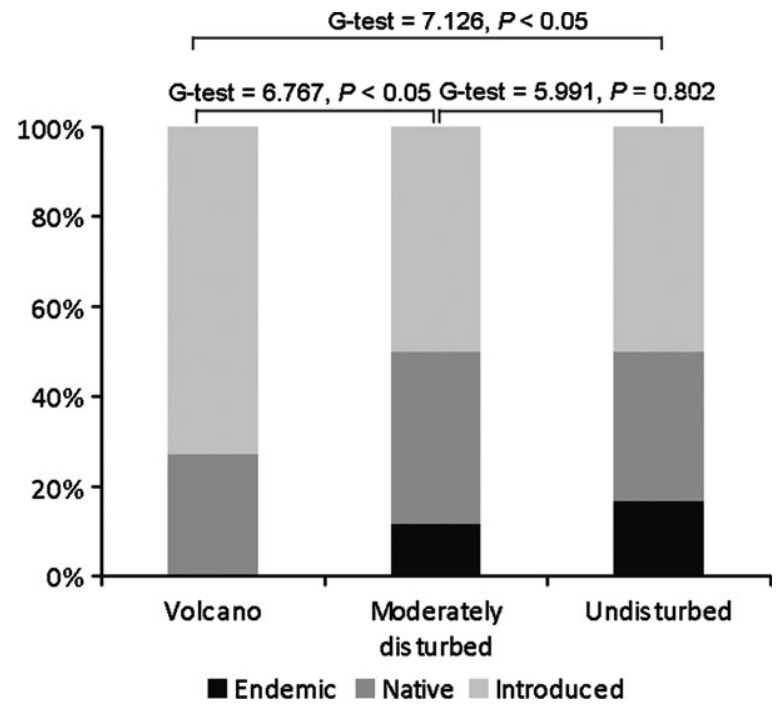

Fig. 1. Percentages of introduced, native and endemic arthropod species in the three investigated sites on Faial Island (Azores), with results of $G$-tests. 
contrast, no significant difference was found between the moderately disturbed and the undisturbed sites $(G$-test $=5.991$, $P=0.802$ ).

All diversity indexes had significantly different values between the erupted volcano and the undisturbed site $(P<0.001$ in all cases) (Table 1). Significant differences were also found for all indexes between the moderately disturbed site and the undisturbed site $(P<0.001$ in all cases) (Table 1$)$. By contrast, no index showed a significant difference between the volcano and the moderately disturbed site $(0.05<P<0.843)$. In particular, the two disturbed sites showed significantly lower values of diversity and evenness $\left(H, e^{H} / S, D\right.$ and $\left.J\right)$ when compared with the undisturbed site, which had, in contrast, a significantly lower value of dominance $(C)$ (Table 1).

Because the volcano and the undisturbed site had similar total species richness, we could not apply equation 1 . However, this was mostly due to the high incidence of introduced taxa in the faunal composition of the volcano community. If introduced species are removed, the current arthropod fauna of the erupted volcano includes seven species, whereas 12 species are found in the undisturbed site. Substitution of $t=43$ (years from the eruption) into equation 1 yielded a relaxation time of about 49 years, with $90 \%$ recolonisation completed in 113 years. A separate analysis for the native non-endemic species gave a relaxation time of $<21$ years, with $90 \%$ recolonisation completed in some 50 years. Calculations were not applicable to the endemic species because none of them was found on the erupted volcano. Overall, these results indicate that recolonisation kinetics was very different between the three categories. The introduced species are the most able to colonise the erupted volcano, reaching a higher richness than in the undisturbed site. The native species need some 50 years for a complete recolonisation, but endemics seems to be unable to recolonise.

Results of similarity analysis are reported in Fig. 2. Similarity between undisturbed and moderately disturbed sites showed a similar value (about $25 \%$ ) for all three categories (total, introduced and native species). When the volcano community was compared with undisturbed site, similarity was very low, with a similar value (about 7\%) for all categories. The three categories, however, showed important differences for the similarity between volcano and moderately disturbed sites. In this comparison, introduced species showed a similarity of about $24 \%$, whereas native species had a similarity of $<10 \%$.

\section{Discussion}

The epigean arthropod fauna of Faial Island represents an excellent opportunity for investigating the recolonisation time in recently formed land. It is reasonable to assume that the frequency with which epigean arthropods colonise new land recently created in an island is in large part determined by the resources becoming available in the new terrain, but also by the intrinsic characteristics of species such as their dispersal ability and life history characteristics. The pool of species we considered here (equilibrium site) is located in the most pristine sector of the island inside a volcanic caldera. The intermediate disturbed site is located at mid-altitude and was heavily impacted by the ashes

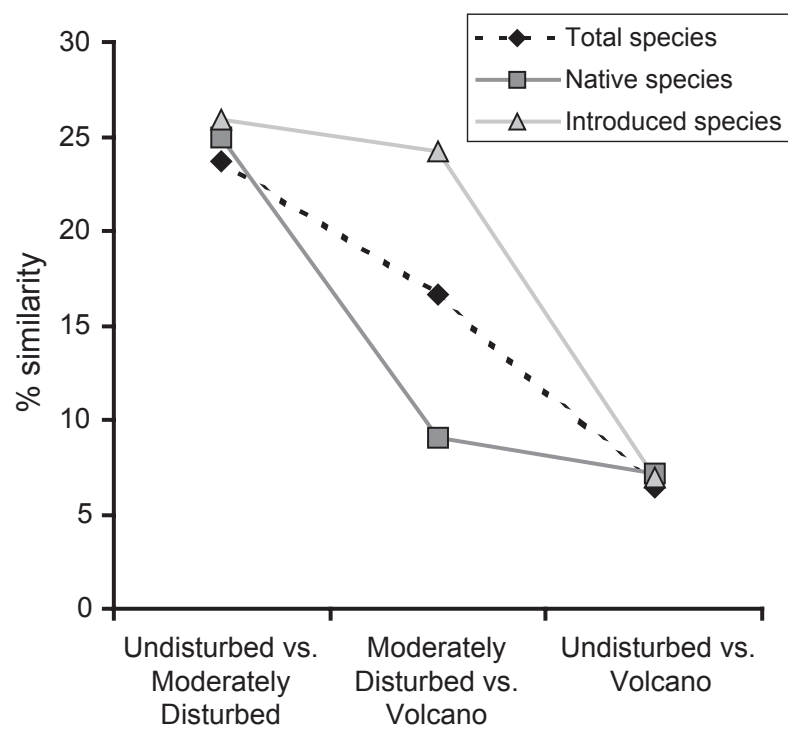

Fig. 2. Percentage similarities (Jaccard index) for total, introduced and native non-endemic arthropod species between the three investigated sites on Faial Island (Azores).

of the coastal Capelinhos Volcano. The group of taxa investigated includes arachnids, millipedes, centipedes and insects with very different life histories. Thus, the selection of these three areas is satisfying two criteria: (i) they provide a good span of biotope ages and disturbance; and (ii) a standardised survey is available for a wide range of arthropod taxa. However, limitations of this data set are as follows: (i) the biological data are a snapshot in time; and (ii) the three areas have very different habitats and vegetation cover. However, we are limiting the effect of habitat differences based on the fact that at least the data are comparable in terms of sampling intensity and in using only soil epigean fauna. Moreover, both the pristine and intermediate disturbed sites are dominated by native vegetation (see Gaspar et al., 2008).

The arthropods of Capelinhos Volcano seem to have a quite short recolonisation time (expressed as the length of time that a given animal group requires for returning to equilibrium value), compared with that calculated for various arthropod groups on island and mainland volcanoes (Fattorini, 2010). However, this is a consequence of striking differences in the pool of species available for recolonisation and accessibility of the erupted area. Capelinhos is a volcano within an island, which has important implications. First, the source pool of species available for recolonisation is mostly restricted to that of the undisturbed adjacent sectors of the island, because immigrations from undisturbed sites within the islands are much more probable than immigrations from adjacent islands or mainlands. In fact, we found, in the disturbed site, more species than in our control site. This is attributable to the arrival of non-indigenous species, absent from the control site, but present in other locations of the islands, namely man-made habitats (exotic plantations, agricultural fields, semi-natural pastures, intensive pastures) and native habitats (secondary Erica azorica/Piccconia azorica habitats; mixed secondary forests). 
Second, species occurring on oceanic islands are filtered among the mainland taxa showing the highest dispersal ability. In this respect, the arthropod fauna of the undisturbed areas which represents the baseline communities for the recolonisation of the erupted volcano will be essentially represented by those species that were able to colonise the island, and which are therefore particularly able to colonise empty areas. In fact, there is a high similarity between the control undisturbed site and the moderately disturbed site, showing that after more than 300 years, many native and endemic species already colonised the old mid-aged volcano. Actually, island endemics, which usually do not show such characteristics, did not yet colonise the erupted volcano.

Third, because of their high isolation, the Azorean Islands are particularly poor in species, when compared with other archipelagos (Borges \& Hortal, 2009; Cardoso et al., 2010). In previous works on island recolonisation, calculations involved volcanoes that were not a part of an island, but that formed the entire island, and richness of other islands was used as equilibrium values (see Fattorini, 2010). Obviously, assuming as species richness the entire fauna of another island implies a much larger baseline than that of the species richness of a sampling plot. Thus, previous works on island volcanoes were addressed to study recolonisation of entire island biotas, whereas we are faced with a recolonisation of a small volcanic area within an island. Recolonisation of erupted islands requires new arrivals from adjacent islands or the nearest mainland, which is much more difficult than recolonisation of a site from an adjacent one within the same island. From this respect, Capelinhos Volcano parallels the case of a mainland volcano; however, recolonisation of mainland volcanoes involve a very large number of species because there are no strong isolation effects (Fattorini, 2010). Thus, a combination of a small number of species in the pool and a great accessibility for recolonisation may explain the short recolonisation time for the Capelinhos arthropod fauna.

Recolonisation of Capelinhos Volcano indicates that species with different distributional ranges (endemic, native and introduced) have different colonisation kinetics. Arthropod introduced species common in the surrounding man-made habitats (such as intensive pastures and exotic forests, especially of Pittosporum undulatum and Cryptomeria japonica) were particularly fast in colonising the erupted volcano, and, in $<50$ years, they reached a number of species superior than that observed in the undisturbed area. This conforms to the high ecological plasticity of these species. By contrast, native non-endemic species have more difficulty in recolonising the erupted area, and no endemic has reached it. Thus, although the erupted volcano has a species richness even slightly higher than that of the undisturbed site, this is a consequence of the high colonisation ability of introduced species common elsewhere in the island. Here, we should refer to the fact that one endemic lavicolous species, the Azorean stone beetle Gietella faialensis (Coleoptera, Gietellidae), is known to be endemic from Capelinhos Volcano (see Menier \& Constantin, 1989), but we were unable to sample it in our standardised samples. However, this is a case of a lavicolous species pre-adapted to the volcanic terrain and therefore could not occur in the two other studied control sites.
These results agree with Fattorini's (2010) conclusions that species with highest dispersal power and colonisation ability are the first to reconstruct their communities, whereas species with low dispersal ability, or that require conditions of mature ecosystems, have long times of recolonisation.

Our study added further momentum to the study of community development during colonisation, providing abundance data. We found that the reconstituted arthropod community of the erupted volcano is very different from that of the undisturbed site also in terms of species abundance distribution. The volcano community is largely dominated by a few species with high abundance and shows depressed values of diversity and evenness in comparison with the undisturbed community. This indicates that it is a strongly dominated (uneven) community, showing a state of affairs typical of pioneer communities.

These results are in agreement with the general model for volcano recolonisation recently proposed by Fattorini (2010). Comparisons with a moderately disturbed site are particularly instructive. Here, species richness is particularly high, and community parameters do not differ from those of the pristine site. These results indicate that we are faced with a well-structured community with more species than expected on the basis of the undisturbed site. This paradoxical result can be explained with reference to the supersaturation phase postulated by Wilson (1969) and evoked by Fattorini (2010), but for which there was little support in the literature. According to Wilson's multi-phase model, in a first phase of colonisation (non-interactive species equilibrium), which occurs soon after colonisation has started, ecological space is unsaturated, and competition, predation and other interactions are limited by low population density. This allows rather fast growth in species richness until a maximum number of species is reached, which may exceed the species richness at a more advanced phase (supersaturation). As population densities increase and biotic interactions within and across trophic levels become more important, the system enters a second phase (interactive species equilibrium). In this second phase, the expected number of species will be lowered, but some species will be very abundant and others very rare. In a third phase ('assortative species equilibrium'), combinations of longer-lived species accumulate, and if the community persists for a long enough period of time, in the last phase (the evolutionary equilibrium), speciation/extinction processes will regulate species richness. This model, which has been postulated for colonisation of entire island biotas (see Fattorini, 2010), may be partially applied - at a smaller scale - to an erupted volcano within an island. Our data suggest that Capelinhos Volcano is in the first phase, as shown by its higher species richness and still low population density. The moderately disturbed site supports the presence of an oversaturation peak and can give an idea of what is expected at the peak of this first phase, with a very large number of species (compared with the undisturbed pristine site), but with some species that have became very abundant and other very scarce. However, the high diversity attained at the intermediate disturbed site' (Cabeço do Fogo) is mainly due to the accumulation of exotic species.

The impact of volcanic eruption was to transform substantially species composition, even in the moderately disturbed site, with only $25 \%$ of species retained. Comparisons between the 
erupted volcano and the moderately disturbed site showed that most of the decrease in similarity from the initial condition was attributable to the lost of native species, with only $7 \%$ of shared species between moderately and severely disturbed sites. By contrast, the percentage of similarity of introduced species shared between the moderately and the severely disturbed sites was similar to that observed between moderately disturbed and undisturbed sites, thus confirming that introduced species are much less sensitive to an increase in the general effects of volcanic activity.

Capelinhos Volcano is a protected area that faces two kinds of threats: (i) the advance of exotic aggressive plant species, a pattern common to all protected areas in Azores (Borges et al., 2005, 2006; Cardoso et al., 2009); and (ii) the build-up of an epigean arthropod community dominated by widespread exotic species. All the native and endemic species require usually at least secondary native vegetation and are able to colonise recent biotopes only in very particular conditions like proximity to source areas and low management intensity (see Meijer et al., 2011). Most of the fauna found in Capelinhos is made up of typical pioneer aeronauts (e.g. spiders, beetles), and the communities are mainly dependent on the biological fallout for feeding (see Ashmole et al., 1992, 1996; Ashmole \& Ashmole, 1997). Many of the populations may not persist or are continuously rescued by immigrants (source-sink dynamics) (Ashmole et al., 1992). Some of the endemic species found in both the pristine and intermediated disturbed sites are particularly common in many habitats in the Azores, such as the spider (Lycosidae) Pardosa acoreensis (see Borges \& Wunderlich, 2008) and the beetle (Elateridae) Heteroderes azoricus (see Cardoso et al., 2009; Meijer et al., 2011). Therefore, we expect that those two endemics will be successful colonisers of Capelinhos in the future.

Our study indicates the following:

1 Introduced species are the most successful colonisers; because future changes in the composition of source pools (expected because of man induced extinction of endemic and native species) will probably increase the proportion of introduced species as available colonisers, newly reconstituted communities will be dominated by these introduced species, not by those which constituted the original community before the perturbation.

2 There is a link between endemicity, low dispersal ability and specialisation: most endemics are virtually unable to recolonise a disturbed site (but see exceptions above), because they move very slowly and are strictly associated with native mature ecosystems.

3 The Capelinhos Volcano needs a long-term management of invasive plants to allow the opportunity for recolonisation by the endemic and native vegetation and consequently increasing the probability of colonisation by indigenous invertebrates.

New volcanic terrain in islands offers a unique opportunity to study the built of invertebrate communities. The study of arthropod colonisation dynamics in island newly formed habitats should continue to be explored in detail in the future.

\section{Acknowledgments}

We are grateful to two anonymous reviewers for their comments on a previous version of this manuscript. J.C. Nunes, volcanologist of University of Azores, helped us with information about the volcanoes. Comments by L.R. Heaney on a first version of Fattorini (2010) paper were particularly useful also for this study. Field work was funded by the Azorean Direção Regional dos Recursos Florestais (Proj. 17.01-080203) and Project ATLANTICO (INTERREG IIIB). P.A.V.B. is currently supported by the Portuguese Foundation for Science and Technology (FCT- PTDC/BIA-BEC/100182/2008 -Predicting extinctions on islands: a multi-scale assessment). We are also grateful to all of the researchers who collaborated in the field and laboratory.

\section{Supporting Information}

Additional Supporting Information may be found in the online version of this article under the DOI reference: doi: 10.1111/ j.1752-4598.2011.00169.x

Appendix S1. Arthropod species abundance in the three samples sites.

Please note: Neither the Editors nor Wiley-Blackwell are responsible for the content or functionality of any supporting materials supplied by the authors. Any queries (other than missing material) should be directed to the corresponding author for the article.

\section{References}

Ashmole, N.P. \& Ashmole, M.J. (1997) The land fauna of ascension island: new data from caves and lava flows, and a reconstruction of the prehistoric ecosystem. Journal of Biogeography, 24, 549-589.

Ashmole, N.P., Oromí, P., Ashmole, M.J. \& Martin, J.L. (1992) Primary faunal succession in volcanic terrain: lava and cave studies on the Canary Islands. Biological Journal of the Linnean Society, 46, 207-234.

Ashmole, N.P., Oromí, P., Ashmole, M.J. \& Martin, J.L. (1996) The invertebrate fauna of early successional volcanic habitats in the Azores. Boletim do Museu Municipal do Funchal, 48, 539.

Biaggini, M., Consorti, R., Dapporto, L., Dellacasa, M., Paggetti, E. \& Corti, C. (2007) The taxonomic level order as a possible tool for rapid assessment of Arthropod diversity in agricultural landscapes. Agriculture, Ecosystems and Environment, 122, 183-191.

Borges, P.A.V., Aguiar, C., Amaral, J., Amorim, I.R., André, G., Arraiol, A., Baz, A., Dinis, F., Enghoff, H., Gaspar, C., Ilharco, F., Mahnert, V., Melo, C., Pereira, F., Quartau, J.A., Ribeiro, S., Ribes, J., Serrano, A.R.M., Sousa, A.B., Strassen, R.Z., Vieira, L., Vieira, V., Vitorino, A. \& Wunderlich, J. (2005) Ranking protected areas in the Azores using standardized sampling of soil epigean arthropods. Biodiversity and Conservation, 14, 2029-2060. 
Borges, P.A.V. \& Brown, V.K. (1999) Effect of island geological age on the arthropod species richness of Azorean pastures. Biological Journal of the Linnean Society, 66, 373-410.

Borges, P.A.V. \& Brown, V.K. (2004) Arthropod community structure in pastures of an island archipelago (Azores): looking for local-regional species richness patterns at small-scales. Bulletin of Entomological Research, 94, 111-121.

Borges, P.A.V. \& Hortal, J. (2009) Time, area and isolation: factors driving the diversification of Azorean arthropods. Journal of Biogeography, 36, 178-191.

Borges, P.A.V., Lobo, J.M., Azevedo, E.B., Gaspar, C., Melo, C. \& Nunes, L.V. (2006) Invasibility and species richness of island endemic arthropods: a general model of endemic vs. exotic species. Journal of Biogeography, 33, 169-187.

Borges, P.A.V. \& Wunderlich, J. (2008) Spider biodiversity patterns and their conservation in the Azorean archipelago, with description of new taxa. Systematics and Biodiversity, 6, 249-282.

Caley, M.J. \& Schluter, D. (1997) The relationship between local and regional diversity. Ecology, 78, 70-80.

Cardoso, P., Arnedo, M.A., Triantis, K.A. \& Borges, P.A.V. (2010) Drivers of diversity in Macaronesian spiders and the role of species extinctions. Journal of Biogeography, 37, 1034 1046.

Cardoso, P., Gaspar, C., Pereira, L.C., Silva, I., Henriques, S.S., Silva, R.R. \& Sousa, P. (2008) Assessing spider species richness and composition in Mediterranean cork oak forests. Acta Oecologica, 33, 114-127.

Cardoso, P., Lobo, J.M., Aranda, S.C., Dinis, F., Gaspar, C. \& Borges, P.A.V. (2009) A spatial scale assessment of habitat effects on arthropod communities of an oceanic island. Acta Oecologica, 35, 590-597.

Diamond, J.M. (1972) Biogeographic kinetics: estimation of relaxation times for avifaunas of Southeast Pacific Islands. Proceedings of the National Academy of Sciences USA, 69, 3199-3203.

Fattorini, S. (2009) Darkling beetle communities in two geologically contrasting biotopes: testing biodiversity patterns by microsite comparisons. Biological Journal of the Linnean Society, London, 98, 787-793.

Fattorini, S. (2010) Biogeographical kinetics on mainland and island volcanoes. Journal of Biogeography, 36, 1100-1110.

Forjaz, V.H. (ed.) (2007) Vulcão dos Capelinhos - memórias 1957-2007. OVGA - Observatório Vulcanológico e Geotérmico dos Açores.

Gaspar, C., Borges, P.A.V. \& Gaston, K.J. (2008) Diversity and distribution of arthropods in native forests of the Azores archipelago. Arquipélago Life and marine Sciences, 25, 1-30.

Gillespie, R.G. \& Clague, D.A. (eds) (2009) Encyclopedia of Islands. University of California Press, Berkeley, California.

Gotelli, N.J. \& Colwell, R.K. (2001) Quantifying biodiversity: procedures and pitfalls in the measurement and comparison of species richness. Ecology Letters, 4, 379-391.

Hammer, Ø., Harper, D.A.T. \& Ryan, P.D. (2001) PAST - palaeontological statistics, ver. 1.89. Palaeontologia Electronica, 4, $1-9$.

Hausdorf, B. \& Hennig, C. (2005) The influence of recent geography, palaeogeography and climate on the composition of the fauna of the central Aegean Islands. Biological Journal of the Linneaen Society, 84, 785-795.

Hayek, L.C. \& Buzas, M.A. (2010) Surveying Natural Populations. Quantitative Tools for Assessing Biodiversity. Columbia University Press, New York.

Krebs, C.J. (1999) Ecological Methodology. Harper and Row, New York.
Legendre, P. \& Legendre, L. (1998) Numerical Ecology, 2nd edn. Developments in Environmental Modelling, Elsevier, Amsterdam.

Loreau, M. (2000) Are communities saturated? On the relationship between $\alpha, \beta$, and $\gamma$ diversity. Ecology Letters, 3, 73-76.

Losos, J.B. \& Ricklefs, R.E. (2009) Adaptation and diversification on islands. Nature, 457, 830-883.

MacArthur, R.H. \& Wilson, E.O. (1967) The Theory of Island Biogeography. Princeton University Press, Princeton, New Jersey.

Machado, F., Parsons, W.H., Richards, A.F. \& Mulford, J.W. (1962) Capelinhos eruption of Fayal Volcano, Azores, 19571958. Journal of Geophysical Research, 67, 3519-3529.

Magurran, A.E. (1988) Ecological Diversity and its Measurements. Princeton University, Princeton, New Jersy.

Magurran, A. (2004) Measuring Biological Diversity. Blackwell Publishing, Malden, Massachusetts.

Meijer, S.S., Whittaker, R.J. \& Borges, P.A.V. (2011) The effects of land-use change on arthropod richness and abundance on Santa Maria Island (Azores): unmanaged plantations favour endemic beetles. Journal of Insect Conservation, 15, 505-522.

Menier, J.J. \& Constantin, R. (1989) Description complémentaire et remarques sur la morphologie de Gietella faialensis Menier \& Constantin, 1988. Notes sur la phylogénie, la biologie et la distribution du genre [Coleoptera, Melyridae, Gietellinae]. Revue Francaise de Entomologie (N.S.), 11, 79-84.

Ricklefs, R.E. (2008) Disintegration of the ecological community. The American Naturalist, 172, 741-750.

Schaefer, H., Hardy, O.J., Silva, L., Barracloug, T.G. \& Savolainen, V. (2011) Testing Darwin's naturalization hypothesis in the Azores. Ecology Letters., 14, 389-396.

Shi, G.R. (1993) Multivariate data analysis in palaeoecology and palaeobiogeography - a review. Palaeogeography, Palaeoclimatology, Palaeoecology, 105, 199-234.

Soares, S.M., Schoereder, J.H. \& DeSouza, O.G. (2001) Processes involved in species saturation of ground-dwelling ant communities (Hymenoptera, Formicidae). Austral Ecology, 26, 1-6.

Srivastava, D.S. (1999) Using local-regional richness plots to test for species saturation: pitfalls and potentials. Journal of Animal Ecology, 68, 1-16.

Stuessy, T.F. (2007) Evolution of specific and genetic diversity during ontogeny of island floras: the importance of understanding process for interpreting island biogeographic patterns. Biogeography in a Changing World (ed. by M.C. Ebach and R.S. Tangney), pp. 117-133. CRC Press, Boca Raton, Florida.

Terborgh, J.W. \& Faaborgh, J. (1980) Saturation of bird communities in the West Indies. The American Naturalist, 116, 178-195.

Thornton, I. (2007) Island Colonization. The Origin and Development of Island Communities. Cambridge University Press, Cambridge.

Tonn, W., Magnuson, J.J., Rask, M. \& Toivonen, J. (1990) Intercontinental comparison of small-lake fish assemblages: the balance between local and regional processes. The American Naturalist, 136, 345-375.

Whittaker, R.J. (1995) Disturbed island ecology. Trends in Ecology and Evolution, 10, 421-425.

Whittaker, R.J. \& Fernández-Palacios, J.M. (2007) Island Biogeography: Ecology, Evolution, and Conservation, 2nd edn. Oxford University Press, Oxford, UK.

Whittaker, R.J., Triantis, K. \& Ladle, R.J. (2008) A general dynamic theory of oceanic island biogeography. Journal of Biogeography, 35, 977-994. 
Whittaker, R.J., Triantis, K.A. \& Ladle, R.J. (2009) A general dynamic theory of oceanic island biogeography: extending the MacArthur-Wilson theory to accommodate the rise and fall of volcanic islands. The Theory of Island Biogeography Revisited (ed. by J.B. Losos and R.E. Ricklefs), pp. 88-115. Princeton University Press, Princeton, New Jersey.

Wilson, E.O. (1969) The species equilibrium. Brokhaven Symposia in Biology, 22, 38-47.

Winkler, H. \& Kampichler, C. (2000) Local and regional species richness in communities of surface-dwelling grassland
Collembola: indication of species saturation. Ecography, 23, 385-392.

Accepted 21 July 2011

First published online 19 September 2011

Editor: Calvin Dytham

Associate editor: Raphael K. Didham 